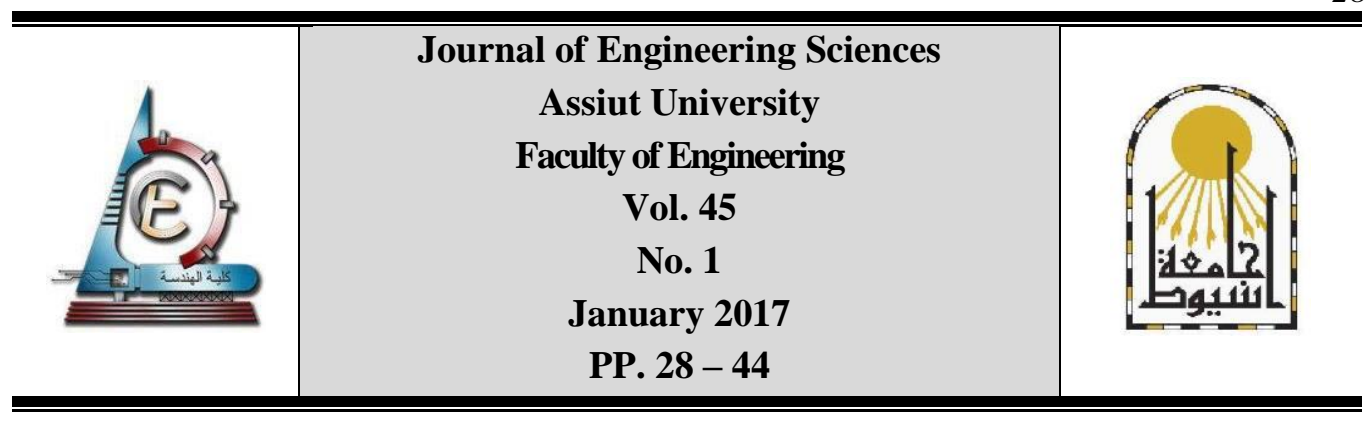

\title{
TRAFFIC ACCIDENTS PREDICTION MODEL USING FUZZY LOGIC: ASWAN DESERT ROAD CASE STUDY
}

\author{
Mohammed Gaber, Amr Mohamed Wahaballa, \\ Ayman Mahmoud Othman, Aboelkasim Diab \\ Department of Civil Engineering, Faculty of Engineering, Aswan University
}

Received 13 November 2016; Accepted 19 December 2016

\begin{abstract}
Transportation system plays an important role in human life and is one of the main indicators of the standard of living. Traffic accidents represent a major problem threatening people's lives, health, and property. Also, these accidents on roads can threat the management of transportation system. Being unsafe, this system will be unable to work properly. Therefore, traffic accidents prediction models may help for understanding accident causes and the number of their occurrence under certain circumstances.

This study aims at developing a prediction model for Aswan western desert road by using fuzzy logic which is known for its benefits in dealing with uncertainty problems. This is to be carried out by the use of actual accident data obtained from the Egyptian General Authority for Roads, Bridges, and Land Transport (GARBLT) with survey data for pavement conditions, traffic flow presented as average hourly traffic per lane (AHTL), speed, minor access, traffic signs conditions and road width which are the inputs of the model.

Several types of model were developed using the Poisson regression model, negative binomial regression model and negative multinomial model based on generalized linear regression technique. On the contrary, the relationship between an accident and the influencing factors is nonlinear and complicated and the using of fuzzy is preferable because fuzzy logic system is good for dealing with nonlinear input and output relationship. The overall results of the study reveal that the predicted results using the proposed fuzzy logic system produce accurate and stable traffic accident predictions.

Keywords: Accidents, Prediction model, Fuzzy logic

\section{Introduction}

Accidents cause injuries and death for many people all over the world annually creating severe social and economic impacts that affect the national economy. In Egypt, vehicle accidents remain a major safety concern, with more than 12,000 deaths per year [1]. Aswan governorate suffers from a serious problem of road accidents threatening people's lives, health, and property. To handle this problem, sophisticated measures need to be addressed.
\end{abstract}

\footnotetext{
* Corresponding author.

E-mail address: moigaber2015@gmail.com
} 
There are many requirements to operate and manage properly. One of most important requirements is that they should be safe. Although the efforts made by the government to prevent or alleviate accidents, there are still many accidents on the Aswan's highways.

In this paper, a fuzzy model is developed for the prediction of accidents rate in Aswan as a case study. Our model is developed by considering long horizon data from 2011 to 2015 for prediction accuracy. Fuzzy logic is applied in order to realize effective and efficient traffic accident prediction. Fuzzy logic approach is proved to be a convenient model for dealing uncertainty phenomena. Many Factors like the traffic features, human elements and environmental suitability cause traffic accidents. Some of these factors may be dynamic (traffic flow) and some may be static (geometry of the road).

The main aim of this paper is to expose the environmental factors of the traffic accidents on the study site into the prediction model. The most effective factors will represent the "input variables" of the fuzzy logic model. Fuzzy logic can be considered to be a generalization of the fuzzy logic system that includes the class of all logic systems with truth values in the interval $(0,1)$.

Roadway and traffic conditions are two major factors affecting traffic accidents. By analyzing these factors, the number of accidents may be reduced. Crash prediction models are found to be effective in the road safety analysis.

\section{A brief review of the past studies is given in the following:}

Wahaballa et al. [2]in their study traffic accident analysis and modeling for upper Egypt rural roads used simple stepwise and multiple regression analysis considering . Four different types of road sections, namely; straight road section in residential areas and unoccupied areas", "curved road section in both or residential areas and unoccupied areas. Then they identified the most influential variables on road accidents. Their results indicated that accident rate is inversely correlated to shoulder width and has direct effect with the number of entrances to the road, and percentage of trucks. Rengarasu et al. [3]studied the effects of road geometry and seasonal changes on head-on and singlevehicle collisions on a rural two lane road.They developed a segmented accident database based on traffic accident analysis system using Poisson-regression models, Rokade et al. [4]developed an accident prediction model using multiple linear regression, input variables used were road cross section dimensions, traffic volume, speed, road shoulder width, lighting conditions, traffic signs and traffic signals. The output of their model was number of accidents. They found that the model gave good results

Traffic accidents problem was solved using fuzzy logic by Driss et al. [5] who identified the degree of exposure to road accident's risk by using traffic accident prediction system based on fuzzy logic which also allows analyzing the level of complexity of the involved factors . Risk factors related to the road's characteristics was identified by the developed system.

Swain et al. [6] mentioned that a fuzzy set allows no sharply defined boundaries because of generalization of a characteristic function of a membership function so the fuzzy set theory is natural and intuitive. Also, several authors observe, that fuzzy logic is a useful technique in real-life transportation problems. For example, Wang et al.[7] worked on a fuzzy logic prediction model, annual average daily traffic (AADT), driving difficulty (DD), velocity (V) and lane width (LW) used as input variables to their model. They found that there was a good relationship between the observations and predicted numbers. Also , Xiao et al. [8] developed two fuzzy logic models for predicting the risk of accidents 
that occurred on wet pavements, the two models were established by using Sugeno inference method and Mamdani inference method.

Meng et al. [9] used fuzzy approach to study road accident frequencies with various traffic and road conditions, taking AADT and traffic load calculated by volume/capacity as the prominent influence factors by the model. The fuzzy logic model they proposed adopts the Mamdani style fuzzy inference. They listed 41 rules to build their model and they found that the model is credible when applying to the study area. Saravanan et al. [10] used fuzzy system to predict accident risk on road network using road, driver, and pedestrian as factors to the fuzzy model .Then they developed a new conceptual framework for accident involvement risk studies. They found that improvements in road condition, locate the accidental intimation board and speed break could decrease accident risk.

One of the most important problems in the field of transportation engineering is the problem of accidents at intersection, the problem was solved using fuzzy logic by Zaied [11 ] who developed a fuzzy logic traffic system for isolated signalized intersections and which is able to change signal timings according to situation level. They found that the proposed system was viable and provides good performance in terms of average waiting time, total moving time, and queue length. Ghanbari et al. [12] introduced a decision support system to select the kind of intelligent transportation system for the highways using fuzzy logic model. The created model was based on Mamadani structure with five input variables including costs, time, the type of highway, the number of lanes, and the significance of the road in terms of security such as accidents, density. They applied the model in a case study of two highways. Their results approved that the prediction by fuzzy logic was viable.

In this paper , annual average volume per lane (AHTL)defined as the number of passing vehicles per hour per lane, road width (rw), speed (sp )defined as the distance per unit of time, number of minor access (ma) along the street over the length of the street in kilometers, road surface condition as percentage ( $\mathrm{pm})$, and the percentile of sign per $\mathrm{km}$ of $\operatorname{road}(\mathrm{sj})$, are taken as inputs to the model. The annual all accidents (AAA) is defined as the number of all accidents occurring on the road in a defined time interval of a day per kilometer length of road is the output. The remainder of this paper is structured as follows. Next section illustrates the study site and data, then the model structure is provided. The results are discussed and followed by the main conclusions of this paper.

\section{Methodology}

\subsection{Study site and data}

The studied section is a part of the western desert road between Aswan and Edfu, which is two directions road of (85) km length, (11.5) m pavement width, (2.0) m shoulders and has speed limit up to $90 \mathrm{~km}$ per hour. This road section has an increasing number of traffic accidents during the last decade. Some of these accidents are serious with many numbers of fatalities. It is possible to solve this problem by categorizing the factors that cause traffic accidents through an accident model. Therefore this paper presents the results of a new analysis of accident data on the desert road by developing a fuzzy model with the aid of AHTL, rw, pm, sj, rw, sp, and ma as inputs to the model. Lighting the road at night and the weather conditions are two factors that have not been taken into consideration in this study because most of the incidents have taken place in the day time and in good weather conditions.

The AHTL was collected by manual survey as shown in Table 1: 
Table 1.

Data points and their representation

\begin{tabular}{|l|l|}
\hline Data point & Representation \\
\hline Desert road between 00.00-01.00 (between 12 a.m. and 1 a.m) & AD1 \\
\hline Desert road between 01.00-02.00 (between 1 a.m. and 2 a.m) & AD2 \\
\hline Desert road between 02.00-03.00 (between 2 a.m. and 3 a.m) & AD3 \\
\hline & $:$ \\
\hline & $:$ \\
\hline Desert road between 10.00-11.00 (between 10 a.m. and 11 a.m) & AD11 \\
\hline & $:$ \\
\hline Desert road between 19.00-20.00 (between $7 p . m$. and 8 p.m) & AD20 \\
\hline Desert road between 21.00-22.00 (between 9 p.m. and 10 p.m) & AD22 \\
\hline
\end{tabular}

The input (pm) refers to the road surface condition and is calculated manually by dividing the road length into sections of two kilometers length and then determining pavement condition index such as shown in Table 2:

Table 2.

Pavement condition index for section (8)

\begin{tabular}{|l|l|l|l|l|}
\hline \multicolumn{1}{|c|}{ Density } & Severity & deduct value & \multicolumn{1}{c|}{$\begin{array}{c}\text { type of defect for right } \\
\text { side }\end{array}$} & Value \\
\hline 0.521739 & M & 1.25 & Bleeding & 120 \\
\hline 1.304348 & L & 0.05 & Bleeding & 300 \\
\hline 1.73913 & M & 7.5 & edge cracking & 400 \\
\hline 0.717391 & L & 9 & alligator cracking & 165 \\
\hline 0.15 & M & 4 & Raveling & 35 \\
\hline 0.08 & L & 0.01 & block cracking & 20 \\
\hline 0.065217 & H & 7 & Rutting & 15 \\
\hline Total & & 29.81 & & \\
\hline Corr & & 21 & & $\sec (8)$ \\
\hline Pci & & $100-21$ & 79 & \\
\hline
\end{tabular}

The input (sp) refers to the speed which is calculated manually by performing a spot speed study. The results are shown in Table 3:

Table 3.

Calculation of spot speed

\begin{tabular}{|l|l|l|l|l|}
\hline \multicolumn{1}{|c|}{ Speed } & Frequency of vehicles & $\begin{array}{c}\text { Cumulative } \\
\text { frequency }\end{array}$ & Cumulative percent & Speed percentile \\
\hline 52.94 & 4 & 4 & $4 \%$ & \\
\hline 56.25 & 8 & 12 & $12 \%$ & \\
\hline 60 & 30 & 42 & $42 \%$ & \\
\hline 64.28 & 16 & 58 & $58 \%$ & \\
\hline 69.23 & 15 & 73 & $73 \%$ & \multirow{2}{*}{$85 \%$} \\
\hline 75 & 8 & 81 & $81 \%$ & \\
\hline 81.8 & 17 & 98 & $98 \%$ & \\
\hline 100 & 2 & 100 & $100 \%$ & \\
\hline
\end{tabular}


JES, Assiut University, Faculty of Engineering, Vol. 45, No. 1, January 2017, pp.28-44

The input (sj) is evaluated by finding the number of signs along the road length; damaged signs or unclear and inadequate signs were not counted. Then the sj equals the number of traffic signs divided by the road length.The input ma refers to the minor access along road length.

In constructing the fuzzy model, the data was separated randomly into two parts: The data points are selected for the construction and the data points are selected for testing the model. The following Tables show the statistics of each of them:

Table 4.

Descriptive statistics of the variables of the calibration set of data:

\begin{tabular}{|l|l|l|l|l|}
\hline & Min & Max & Mean & St. Dev. \\
\hline AHTL & 120 & 287 & 181 & 51.3 \\
\hline $\mathrm{Rw}$ & 10.25 & 12.0 & 11.5 & .586302 \\
\hline $\mathrm{Sp}$ & 75 & 90 & 83 & 5.225 \\
\hline $\mathrm{Ma}$ & .05 & .05 & .05 & 0.0 \\
\hline $\mathrm{Sj}$ & .62 & .62 & .62 & 0.0 \\
\hline $\mathrm{Pm}$ & .85 & .05 & .60 & .284 \\
\hline
\end{tabular}

Table 5.

Descriptive statistics of the variables of the testing set of data

\begin{tabular}{|l|l|l|l|l|}
\hline Variable & Min & Max & Mean & St. Dev. \\
\hline AHTL & 96 & 306 & 176 & 49.4333 \\
\hline $\mathrm{Rw}$ & 10.25 & 12.0 & 11.5 & .586302 \\
\hline $\mathrm{Sp}$ & 72 & 90 & 81.5 & 4.71 \\
\hline $\mathrm{Ma}$ & .05 & .05 & .05 & 0.0 \\
\hline $\mathrm{Sj}$ & .62 & .62 & .62 & 0.0 \\
\hline $\mathrm{Pm}$ & .85 & .05 & .60 & .284 \\
\hline
\end{tabular}

Accident data used in this study was obtained from recorded data of the Egyptian General Authority for Roads, Bridges, and Land Transport (GARBLT) [13]. These are shown in the following Table:

Table 6.

Sample of accidents data based on GARBLT

\begin{tabular}{|l|l|l|l|}
\hline hour & Year & alignment & Cause \\
\hline $7 \mathrm{am}$ & 2015 & Straight & over speeding \\
\hline $2 \mathrm{pm}$ & 2014 & Straight & over speeding \\
\hline $4 \mathrm{pm}$ & 2014 & Straight & tire exploding \\
\hline $3 \mathrm{pm}$ & 2014 & Straight & over speeding \\
\hline $8 \mathrm{am}$ & 2014 & Straight & over speeding \\
\hline $5.3 \mathrm{am}$ & 2015 & Straight & over speeding \\
\hline $4 \mathrm{am}$ & 2015 & Straight & tire exploding \\
\hline $8 \mathrm{pm}$ & 2014 & Straight & over speeding \\
\hline $10 \mathrm{am}$ & 2013 & Straight & over speeding \\
\hline $6 . \mathrm{pm}$ & 2014 & Straight & over speeding \\
\hline $11 \mathrm{am}$ & 2014 & Straight & over speeding \\
\hline $2.0 \mathrm{am}$ & 2014 & Straight & over speeding \\
\hline
\end{tabular}

These different data are used to construct the model as shown in Figure 1: 


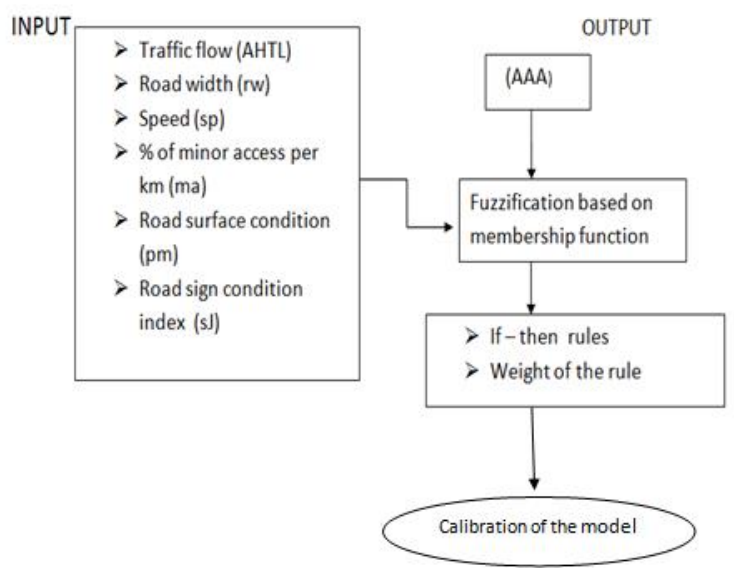

Fig. 1. Structure of the model

The inference system used is Mamdani's inference method [14], which is among the first system to use fuzzy logic. According to Ross [15] fuzzy systems consists of steps as shown in the Figure below:



Fig. 2. Fuzzy system

Mamdani fuzzy inference:

The Mamdani-style fuzzy inference process is performed in four steps:

- Fuzzification of the input variables,

- Rule evaluation, fuzzy expert systems make use of the classical fuzzy operation union:

$$
\mathrm{m}_{\mathrm{AB}}(\mathrm{x})=\max \left[\mathrm{m}_{\mathrm{A}}(\mathrm{x}) \cup \mathrm{m}_{\mathrm{B}}(\mathrm{x})\right]
$$

And in order to evaluate the conjunction of the rule antecedents, we apply the AND fuzzy operation intersection:

$\mathrm{m}_{\mathrm{AB}}(\mathrm{x})=\min \left[\mathrm{m}_{\mathrm{A}}(\mathrm{x}) \cap \mathrm{m}_{\mathrm{B}}(\mathrm{x})\right]$

- Aggregation of the rule outputs, and finally

- Defuzzification.

The fuzzy logic System works on mapping a set of crisp inputs to a set of crisp outputs. A fuzzifier converts crisp inputs into fuzzy values. Fuzzification is used to find grades of membership for each value in the input set .At first we start with defining every variable of the inputs by membership sets. Fuzzy set membership is given by degree of membership which is a value between 0 and 1 . A fuzzy set consists of a linguistic term and a membership value. 
The most commonly used membership functions have shapes such as triangular and trapezoidal.

The triangular membership function with straight lines can be defined according to the following figure and illustrations:

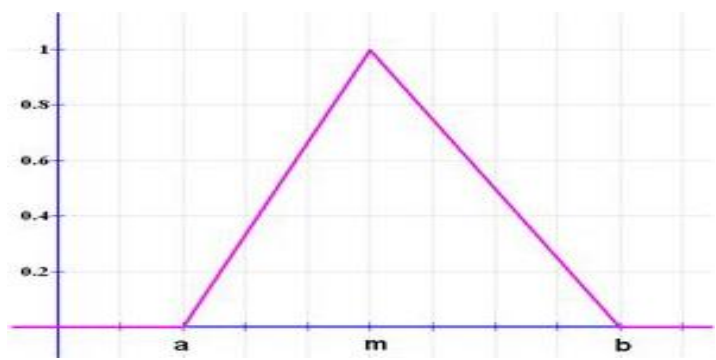

Fig. 3. The triangular membership

$\mathrm{F}(\mathrm{u}: \mathrm{a}, \mathrm{m}, \mathrm{b})=0 \quad \mathrm{a}>\mathrm{u}$

$=(\mathrm{u}-\mathrm{a}) /(\mathrm{m}-\mathrm{a}) \quad \mathrm{a} \leq \mathrm{u} \leq \mathrm{m}$

$=(\mathrm{b}-\mathrm{u}) /(\mathrm{b}-\mathrm{m}) \quad \mathrm{m} \leq \mathrm{u} \leq \mathrm{b}$

$=0 \quad \mathrm{~b}<\mathrm{u}$

Trapezoidal membership function with straight lines can be defined according to the following figure and illustrations.

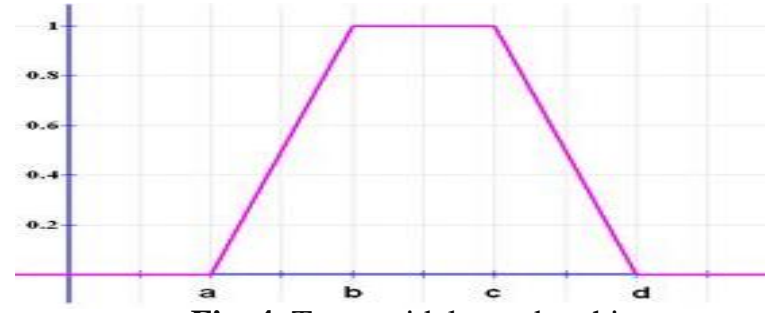

Fig. 4. Trapezoidal membership

$$
\begin{array}{llll}
F(x, a, b, c, d)=0 & \text { if } & x<a, x>d \\
=(x-a) /(b-a) & \text { if } & a \leq x \leq b \\
=1 & \text { if } & b \leq x \leq c \\
=(d-x) /(d-c) & \text { if } & c \leq x \leq d
\end{array}
$$

The fuzzification is the initial process of a fuzzy model where fuzzy subsets of universal sets of fuzzy variable are constructed, according to two main stages: derivation of the membership functions for both input and output variables and the linguistic representation of these functions. Different types of membership functions can be applied for fuzzification such as triangular, trapezoidal, Gaussian, etc. Triangular and trapezoidal waveforms were applied for the fuzzy model of this paper.

\subsection{Developing of fuzzy accidents model}

\subsubsection{Fuzzification of the Input Variables}

The variable AHTL is divided into three triangular fuzzy subsets due to the distribution of the data as shown in Figure 5 



Fig. 5. Membership function of AHTL

Mathematical Expressions of the variable AHTL (dimensionless)

$$
\begin{array}{lll}
\mu_{\text {light }}=\frac{A H T l}{99} & , \text { IF } & 0 \leq \text { AHTL } \leq 99 \\
\mu_{\text {light }}=\frac{165-A H T L}{165-99} & \text {, IF } & 99 \leq \text { AHTL } \leq 165 \\
\mu_{\text {med }}=\frac{A H T L-99}{165-99} & \text {, IF } & 99 \leq \text { AHTL } \leq 165 \\
\mu_{\text {med }}=\frac{223-A H T L}{223-165} & \text {, IF } & 165 \leq \text { AHTL } \leq 223 \\
\mu_{\text {high }}=\frac{A H T L-165}{223-165} & , \text { IF } & 165 \leq \text { AHTL } \leq 223 \\
\mu_{\text {high }}=1 & , \text { IF } & 223 \leq \text { AHTL }
\end{array}
$$

the input varible pm indicated by two $(0,0.85)$ varables as shown in Figure:



Fig. 6. Membership function of pm

$$
\mu_{\text {bad }}=\frac{.85-P M}{.85-0} \quad, \text { IF } \quad 0 \leq \mathrm{pm} \leq .85
$$




$$
\mu_{\text {good }}=\frac{P M}{.85} \quad, \text { IF } \quad 0 \leq \mathrm{pm} \leq .85
$$

the input varible speed indicated by two $(0,110)$ varables as shown

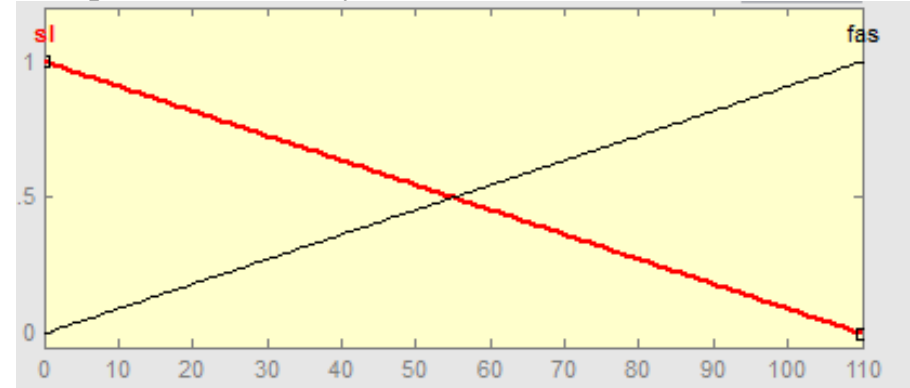

Fig. 7. Membership function of $\mathrm{sp}$

$\mu s_{L}=\frac{110-S p}{110-0} \quad$, IF $\quad 0 \leq$ speed $\leq 110$

$\mu_{\text {fas }}=\frac{s p}{110} \quad$, IF $\quad 0 \leq$ speed $\leq 110$

the input varible ma indicated by two $(0,0.1)$ varables as shown

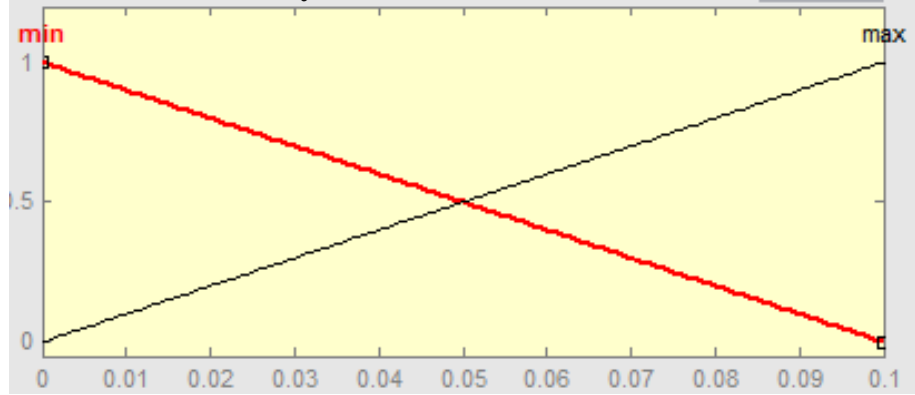

Fig. 8. Membership function of ma

$$
\begin{array}{lll}
\mu_{\min }=\frac{.1-m a}{.1-0} & , \text { IF } & 0 \leq \mathrm{ma} \leq .1 \\
\mu_{\max }=\frac{m a}{.1} & \text {, IF } & 0 \leq \mathrm{ma} \leq .1
\end{array}
$$

the input varible s.j indicated by two $(0,0.85)$ varables as shown:

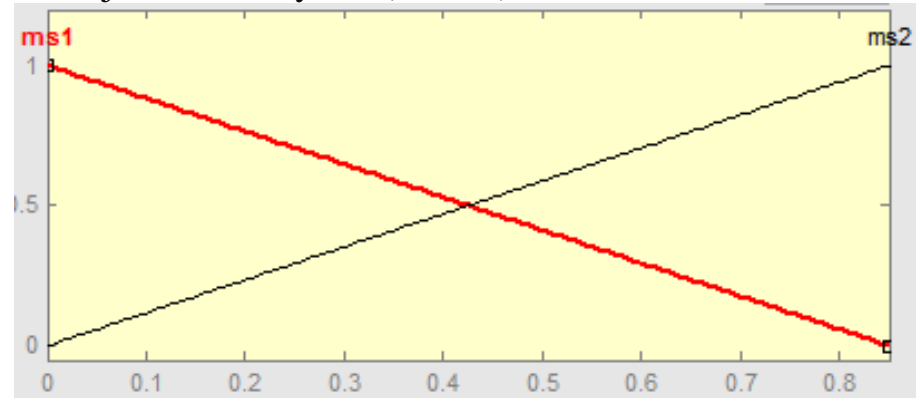

Fig. 9. Membership function of $\mathrm{sj}$

$\mu_{\mathrm{ms} 1}=\frac{.85-S J}{.85-0} \quad$, IF $\quad 0 \leq \mathrm{SJ} \leq .85$

$\mu_{\mathrm{ms} 2}=\frac{S J}{.85} \quad$, IF $\quad 0 \leq \mathrm{SJ} \leq .85$

the input varible rw indicated by two $(0,15)$ varables as shown 


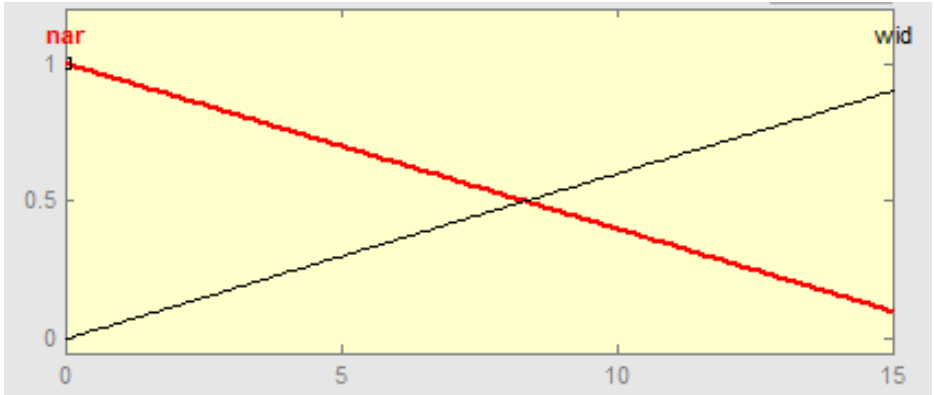

Fig. 10. Membership function of rw

$$
\begin{array}{lll}
\mu_{\text {nar }}=\frac{15-r w}{15-0} & \text {, IF } & 0 \leq \mathrm{rw} \leq 15 \\
\mu_{\text {wid }}=\frac{r w}{15} & \text {, IF } & 0 \leq \mathrm{rw} \leq 15
\end{array}
$$

\subsubsection{Fuzzification of the output variable}

\section{-FOR AAA}
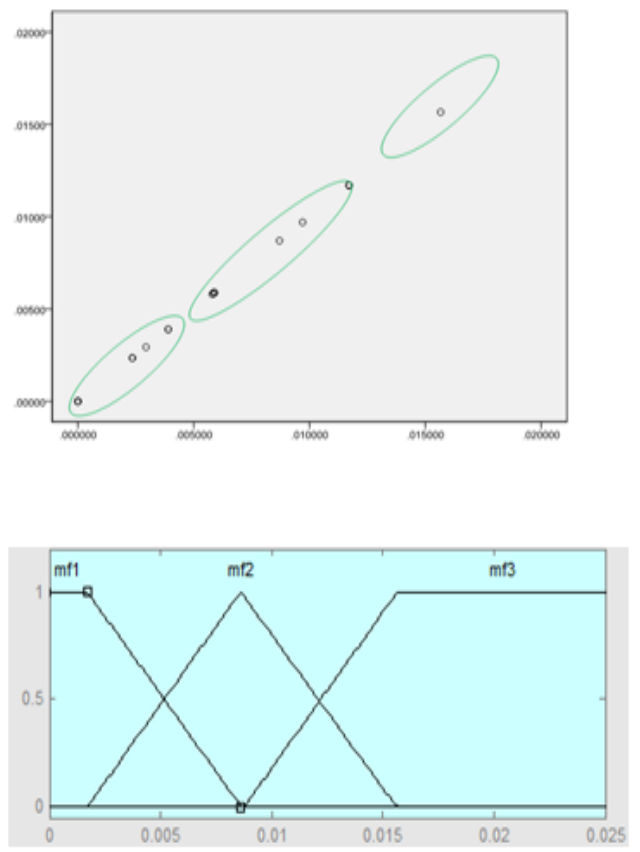

Fig. 11. Membership function of AAA

Mathematical Expressions of the variable AAA:

$$
\begin{aligned}
& \mu_{\mathrm{mfl}}=1 \quad \text {, IF } \quad 0 \leq \mathrm{AAA} \leq .0017 \\
& \mu_{\mathrm{mfl}}=\frac{.0086-A A A}{.0086-.0017} \quad \text {, IF } \quad 0.0017 \leq \mathrm{AAA} \leq .0086 \\
& \mu_{\mathrm{mf} 2}=\frac{.0 A A-.0017}{.0086-.0017} \quad \text {, IF } \quad 0.0017 \leq \mathrm{AAA} \leq .0086 \\
& \mu_{\mathrm{mf} 2}=\frac{.0156-A A A}{.0156-.0086} \quad \text {, IF } \quad 0.0086 \leq \mathrm{AAA} \leq .0156 \\
& \mu_{\mathrm{mf} 3}=\frac{A A A-.0086}{.0156-.0086} \quad \text {, IF } \quad 0.0086 \leq \mathrm{AAA} \leq .0156 \\
& \mu_{\mathrm{mf} 3}=1 \quad \text {, IF } 0.0156 \leq \mathrm{AAA}
\end{aligned}
$$




\subsubsection{Production of the rule base}

In this study, fuzzy rules relating input variables to output variable were constructed from the calibration data set according to the rule construction procedure given in the literature (Tayfur [16]). In the case study, six input variables with its subsets taken altogether, $(3 \times 2 \times 2 \times 2 \times 2 \times 2=96)$. The rules were formulated through the combinations of the data separated as calibration group. Contradicting rules were omitted intuitively and the model constructed with the 11 rules derived from the calibration data.

Examples from the rule_list:

$1-(A h t l=m e d) \&(r w=$ wide $) \&($ speed $=s l o) \&(m a=m i n) \&(p m=b a d) \&(s j=m s 2)$ then $(A A A=m f 1)$

2- $($ Ahtl=light $) \&(r w=$ wide $) \&($ speed $=s l o) \&($ ma $=$ max $) \&(p m=$ good $) \&(s j=m s 1)$ then $(A A A=m f 1)$

Next stage is the defuzzification of all aggregated fuzzy sets into output crisp values. (MATLAB 7.8.0.347 - fuzzy logic toolbox) is used as a computing tool to obtain the crisp values from the each fuzzy output set.

\subsubsection{Defuzzification process}

This is the process of converting each aggregated fuzzy output into a single crisp value through the developed fuzzy rules. CoG defuzzification method is the most popular defuzzification technique and is widely utilized in actual applications was applied for the model. Following equation is the mathematical expression of the $\mathrm{CoG}$ defuzzification method for the fuzzy system.

\section{Results}

\subsection{The evaluation of the model versus actual data}

The following Figure shows a sample set of defuzzified data point AD15 from testing group of data.

$$
u(k T)=\frac{\sum_{i=1}^{N} u_{i} \mu_{M}\left(u_{i}\right)}{\sum_{i=1}^{N} \mu_{M}\left(u_{i}\right)}
$$

\subsection{Sensitivity analysis}

For the analysis process the value of AHTL, ma, sj, rw, pm, and sp are taken as 176, $0.05,0.62,11.5,81.5$ respectively.

We can find the effect of each variable based on the proposed model, as shown in the following:

\subsubsection{The effect of $r w$}

The evaluation process was carried out by taking the value of $r w=11.5$ and the effect of changing the value of rw to 14 and 15 as shown in Table 7:

Table 7.

The effect of changing in rw on AAA (rw 8.1\%):

\begin{tabular}{|l|l|l|l|l|l|l|}
\hline AHTL & Sp & Rw & Ma & Pm & Sj & AAA \\
\hline 176 & 81.5 & 11.5 & .05 & .6 & .62 & .00767 \\
\hline 176 & 81.5 & 14 & .05 & .6 & .62 & .00749 \\
\hline 176 & 81.5 & 15 & .05 & .6 & .62 & .00707 \\
\hline
\end{tabular}




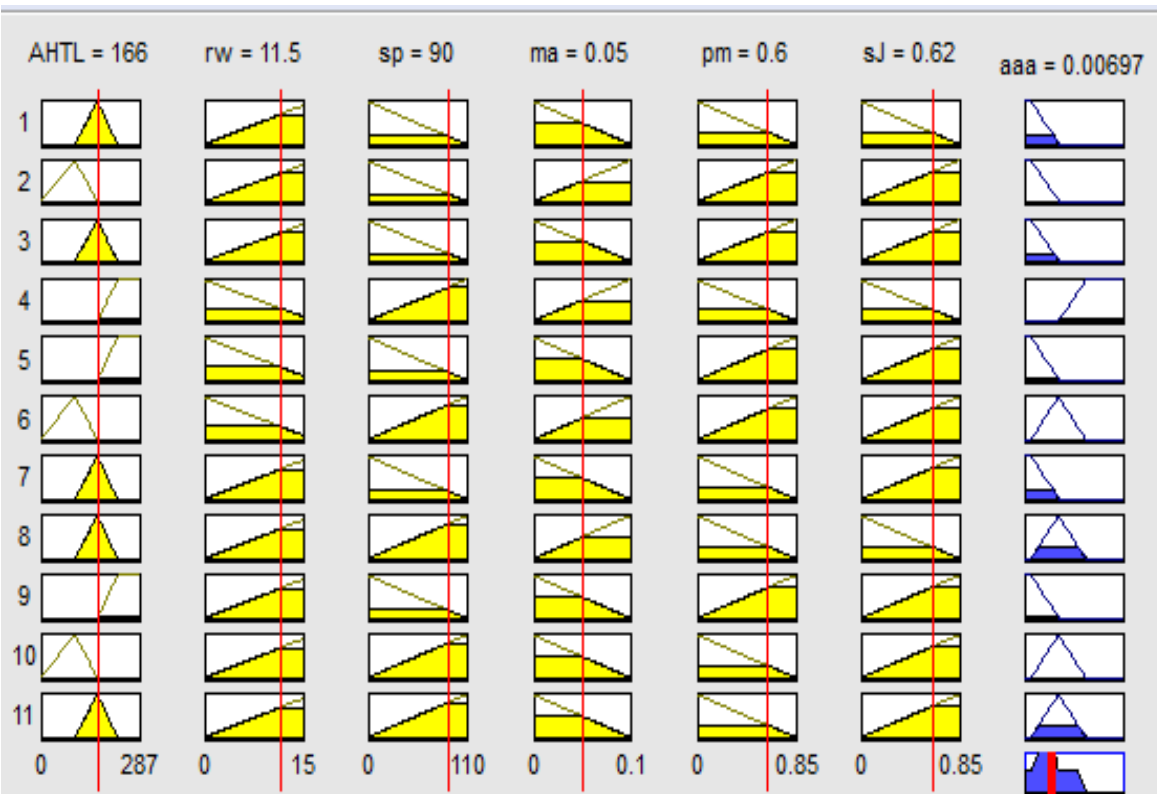

Fig. 12. Deffuzification of the data point AD15 (Fuzzy Logic Toolbox)

\subsubsection{The effect of $s p$}

The evaluation process was carried out by taking the value of $\mathrm{sp}=90$ and the effect of changing it as shown in Table8:

Table 8.

The effect of changing in sp on AAA (sp 7.4\%)

\begin{tabular}{|l|l|l|l|l|l|l|}
\hline AHTL & $\mathrm{Sp}$ & $\mathrm{Rw}$ & $\mathrm{Ma}$ & $\mathrm{Pm}$ & $\mathrm{Sj}$ & AAA \\
\hline 176 & 60 & 11.5 & .05 & .6 & .62 & .00734 \\
\hline 176 & 70 & 11.5 & .05 & .6 & .62 & .00746 \\
\hline 176 & 75 & 11.5 & .05 & .6 & .62 & .00752 \\
\hline 176 & 80 & 11.5 & .05 & 0.6 & .62 & .00762 \\
\hline 176 & 90 & 11.5 & .05 & .6 & .62 & .00812 \\
\hline
\end{tabular}

\subsubsection{The effect of $m a$}

The evaluation process was carried out taking the value of ma=.05 and the effect of changing value of ma to 0 such as shown in Table 9:

Table 9.

The effect of changing in ma on AAA (Well controlled of minor access helps in decreasing aaa by $32 \%$ )

\begin{tabular}{|l|l|l|l|l|l|l|}
\hline AHTL & $\mathrm{Sp}$ & $\mathrm{Rw}$ & $\mathrm{Ma}$ & $\mathrm{Pm}$ & $\mathrm{Sj}$ & AAA \\
\hline 176 & 81.5 & 11.5 & 0 & .6 & .62 & .00522 \\
\hline 176 & 81.5 & 11.5 & .01 & .6 & .62 & .00671 \\
\hline 176 & 81.5 & 11.5 & .02 & .6 & .62 & .00764 \\
\hline 176 & 81.5 & 11.5 & .05 & .6 & .62 & .00768 \\
\hline
\end{tabular}

\subsubsection{The effect of $\mathrm{pm}$ :}

The evaluation process was carried out taking the value of $\mathrm{pm}=0.6$ and the effect of changing value of pm till 0.75 as shown in Table 10: 
JES, Assiut University, Faculty of Engineering, Vol. 45, No. 1, January 2017, pp.28-44

Table 10.

The effect of changing in pm conditions on AAA ( pm 6.12\%)

\begin{tabular}{|l|l|l|l|l|l|l|}
\hline AHTL & Sp & Rw & Ma & Pm & Sj & AAA \\
\hline 176 & 81.5 & 11.5 & .05 & .1 & .62 & .00824 \\
\hline 176 & 81.5 & 11.5 & .05 & .2 & .62 & .0078 \\
\hline 176 & 81.5 & 11.5 & .05 & .3 & .62 & .00776 \\
\hline 176 & 81.5 & 11.5 & .05 & .4 & .62 & .00776 \\
\hline 176 & 81.5 & 11.5 & .05 & .5 & .62 & .00773 \\
\hline 176 & 81.5 & 11.5 & .05 & .6 & .62 & .00768 \\
\hline 176 & 81.5 & 11.5 & .05 & .75 & .62 & .00721 \\
\hline 176 & 81.5 & 11.5 & .05 & .8 & .62 & .00627 \\
\hline
\end{tabular}

3.2.5. The effect of $s j$

The evaluation process was carried out taking the value of $s j=.62$ and the effect of changing value of sj to .75 such as shown in Table 11:

Table11.

The effect of changing in sj conditions on AAA ( sj $6.9 \%$ )

\begin{tabular}{|l|l|l|l|l|l|l|}
\hline AHTL & Sp & Rw & Ma & Pm & Sj & AAA \\
\hline 176 & 81.5 & 11.5 & .05 & .6 & 0 & .0105 \\
\hline 176 & 81.5 & 11.5 & .05 & .6 & .1 & .00849 \\
\hline 176 & 81.5 & 11.5 & .05 & .6 & .2 & .00774 \\
\hline 176 & 81.5 & 11.5 & .05 & .6 & .3 & .00769 \\
\hline 176 & 81.5 & 11.5 & .05 & .6 & .62 & .00768 \\
\hline 176 & 81.5 & 11.5 & .05 & .6 & .75 & .00715 \\
\hline 176 & 81.5 & 11.5 & .05 & .6 & .8 & .00646 \\
\hline
\end{tabular}

\subsubsection{The effect of AHTL}

The evaluation process was carried out such as shown in Table 12:

Table 12 .

The effect of changing in AHTL on AAA (AHTL 28.22 \%)

\begin{tabular}{|l|l|l|l|l|l|l|}
\hline AHTL & Sp & Rw & Ma & Pm & Sj & AAA \\
\hline 176 & 81.5 & 11.5 & .05 & .6 & 0.62 & .00768 \\
\hline 306 & 81.5 & 11.5 & .05 & .6 & .62 & .0107 \\
\hline
\end{tabular}

Where the percentage of heavy trucks $=39 \%$

Then the effect of heavy trucks $=.39 * 28.22=11.33 \%$

The increase of heavy trucks leads to increase traffic accidents by $11.33 \%$ 


\subsection{Crisp results of the fuzzy model}

Table 13.

Comparison between real data and Crisp results of the Fuzzy Model for test set

\begin{tabular}{|l|l|l|}
\hline \multirow{2}{*}{ Data point } & \multicolumn{2}{|c|}{ AAA } \\
\cline { 2 - 3 } & Real & Model \\
\hline AD0 & 0 & 0.00654 \\
\hline AD1 & 0.0058 & 0.0073 \\
\hline AD2 & 0 & 0.0067 \\
\hline AD3 & 0.0117 & 0.00777 \\
\hline AD4 & 0.0117 & 0.00865 \\
\hline AD5 & 0.00294 & 0.00653 \\
\hline AD6 & 0.0117 & 0.00855 \\
\hline AD7 & 0.0087 & 0.00808 \\
\hline AD8 & 0.01566 & 0.101 \\
\hline AD9 & 0.0097 & 0.00808 \\
\hline AD10 & 0.00588 & 0.00681 \\
\hline AD11 & 0.0039 & 0.00679 \\
\hline AD12 & 0.0039 & 0.0074 \\
\hline AD13 & 0.00588 & 0.00686 \\
\hline AD14 & 0.00588 & 0.00689 \\
\hline AD15 & 0.00588 & 0.00692 \\
\hline AD16 & 0.00235 & 0.00659 \\
\hline AD17 & 0.00588 & 0.00777 \\
\hline AD18 & 0 & 0.0067 \\
\hline AD19 & 0.00588 & 0.00784 \\
\hline AD20 & 0.00235 & 0.00674 \\
\hline AD21 & 0.0117 & 0.00844 \\
\hline AD22 & 0.00588 & 0.00841 \\
\hline AD23 & 0 & 0.00666 \\
\hline
\end{tabular}

Model Summary

\begin{tabular}{|l|l|lc|l|}
\hline $\mathrm{R}$ & R Square & $\begin{array}{l}\text { Adjusted } \\
\text { Square }\end{array}$ & $\mathrm{R}$ & RMSD \\
\hline .874 & .761 & .752 & .0017 \\
\hline
\end{tabular}






\subsection{Analysis discussion}

The analysis of results indicates that road accidents on the desert road can be reduced by $7.4 \%$ if the speed is limited to $75 \mathrm{~km}$ per hour. Increasing road width by $3.5 \mathrm{~m}$ helps in decreasing traffic accidents by $8.1 \%$. The results also show that improving of road surface condition $(+15 \%)$ and road signs condition $(+13 \%)$ will decrease road accidents by 6.12 $\%$ and $6.9 \%$ respectively. There will be a decrease of road accidents by $32 \%$ if there is a better control minor access.

\section{Conclusion and recommendations}

This paper presents a model for traffic accident prediction which can be effectively used for transportation planning, management and security assessment at any time. The purpose of the analysis is to develop an accident prediction model and investigate factors contributing to the occurrence of road accidents on highways using data for the selected locations on desert road located in Aswan city as a case study.

Fuzzy inference system based traffic accident prediction algorithm was proposed. The proposed model is established using AHTL, rw, ma, sj, sp and $\mathrm{pm}$ as input variables and AAA as an output variable. The results proved a correlation coefficient of more than $88 \%$ when comparing model predictions with the true data of accidents. Moreover, the analysis is carried out to identify the effect of the input factors as well as to explain the possibility of applying the proposed model. According to the findings of this paper, the recommendations are to be as follows: increasing safety and reducing the phenomenon of traffic accidents on the desert road necessitate an increase of the road width, taking suitable enforcement measures to reduce the speed on the road, remove or repair defects of the road surface, raising the efficiency of traffic signs and full control the side entrances.

\section{References}

[1] Road Safety in Egypt. Department of Injuries and Violence Prevention, Road Traffic Injuries, World Health Organization. [Online]. Available:

http://www.wh.int/violence_injury_prevention/road_traffic/country work/egy/en.

[2] Wahaballa, M., A., Othman,M.,A., and Ahmed,H., (2006) ,Traffic Accident Analysis \&Modeling for Upper Egypt Rural Roads , Mansoura engineering journal

[3] RENGARASU, T. M., HAGIWARA, T., \& HIRASAWA, M. (2007). Effects of road geometry and season on head-on and single-vehicle collisions on rural two lane roads in Hokkaido, Japan. In Proceedings of the Eastern Asia Society for Transportation Studies (Vol. 2007, No. 0, pp. 2860-2872). Eastern Asia Society for Transportation Studies.

[4] Rokade, S., Singh, K., Katiyar, S. K., \& Gupta, S. (2010). Development of accident prediction model. International Journal of Advanced Engineering Technology, 1(3), 25-40.

[5 ] Driss, M., Saint-Gerand, T., Bensaid, A., Benabdeli, K., \& Hamadouche, M. A. (2013, May). A

fuzzy logic model for identifying spatial degrees of exposure to the risk of road accidents

(Case study of the Wilaya of Mascara, Northwest of Algeria). In Advanced Logistics and

Transport (ICALT), 2013 International Conference on (pp. 69-74). IEEE.

[6] Swain, N. K. (2005, March). A survey of application of fuzzy logic in intelligent transportation systems (ITS) and rural ITS. In Proceedings of the IEEE Southeast on 2006 (pp. 85-90). IEEE.

[7] Wang, H., Zheng, L., \& Meng, X. (2011). Traffic accidents prediction model based on fuzzy logic. In Advances in Information Technology and Education (pp. 101-108). Springer Berlin Heidelberg.

[8] Xiao, J., Kulakowski, B., \& EI-Gindy, M. (2000). Prediction of risk of wet-pavement accidents: fuzzy logic model. Transportation Research Record: Journal of the Transportation Research Board, (1717), 28-36. 
[9] MENG, X. H., ZHENG, L., \& QIN, G. M. (2009). Traffic Accidents Prediction and Prominent Influencing Factors Analysis Based on Fuzzy Logic [J]. Journal of Transportation Systems Engineering and Information Technology, 2, 015.

[10] Saravanan, S., Sabari, A., \& Geetha, M. (2014). Fuzzy-based approach to predict accident risk on road network. International Journal of Emerging Technology and Advanced Engineering, 4(5), 536-540.

[ 11] Zaied, A. N. H., \& Al Othman, W. (2011). Development of a fuzzy logic traffic system for isolated signalized intersections in the State of Kuwait. Expert Systems with Applications, 38(8), 9434-9441

[12] Ghanbari, M., Mehr, A. G., \& Nehzat, H. Introducing an Intelligent Transportation System Decision Support Model for the Highways in Iran Based on Fuzzy Logic.

[13] Egyptian General Authority for Roads, Bridges, and Land Transport, (GARBLT)

[14] Mamdani, E. H., \& Assilian, S. (1975). An experiment in linguistic synthesis with a fuzzy logic controller. International journal of man-machine studies, 7(1), 1-13.

[15] Ross, T. J. (2010). Development of membership functions. Fuzzy Logic with Engineering Applications, Third Edition, 174-210.

[16] Tayfur, G., Ozdemir, S., \& Singh, V. P. (2003). Fuzzy logic algorithm for runoff-induced sediment transport from bare soil surfaces. Advances in water resources, 26(12), 1249-1256. 


\section{"التبؤ بحوادث المرور باستخدام المنهج الضبابى الطريق الصحراوى باسوان كحالة دراسة"}

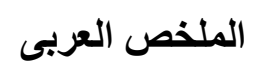

لأنظمة النقل دورا كبير ا في حياة الإنسـان وهى من بين المؤشـر ات الرئيسية لمستوى المعيشـة. وبالتـالي

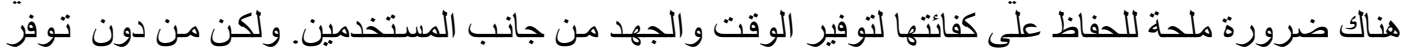

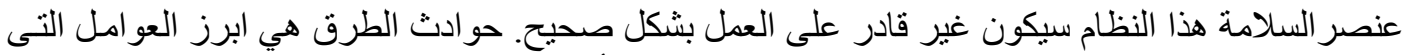



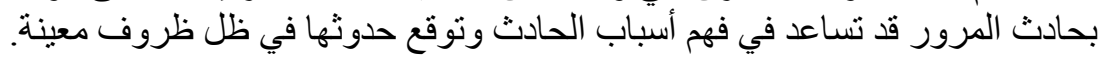

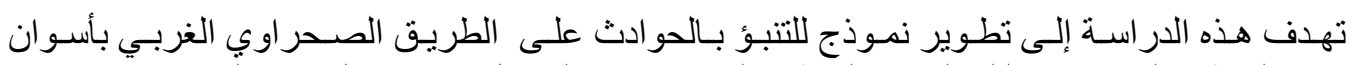

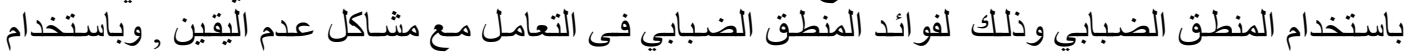

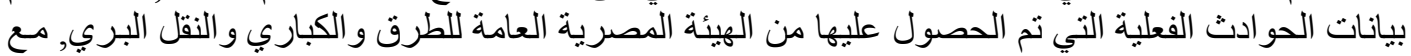

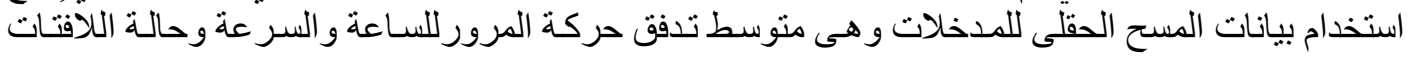

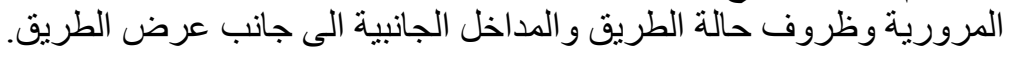

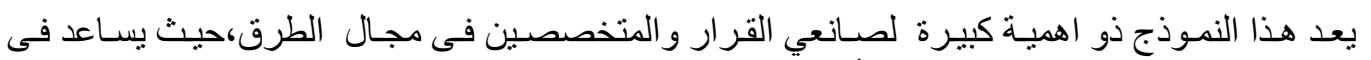

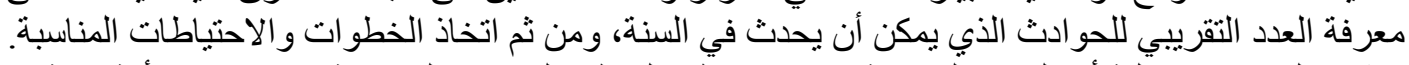

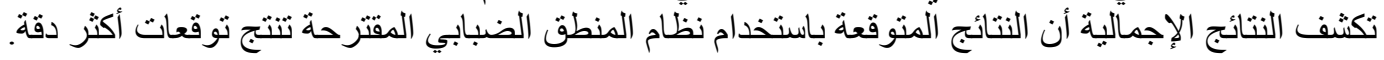

